\title{
A Three-Dimensional Contextualization Established for an English Language-Learning-and-Teaching to Get Along With in the Classroom
}

\author{
YAN Jing, CHEN Si, FEI Zi \\ Northwest University for Nationalities, Lanzhou, China
}

\begin{abstract}
If language is supposed to be the text, the question then comes to "what is the context within which language lives rather than die?". What context to language-learning is what water to plant-surviving. Questionably, what is thought of previously as the context or linguistic environment, especially that for classroom situation, remains still a problem to be dealt with and, what this paper is trying to do is therefore to establish kind of a three-dimensional contextualization, which is hypothesized as being verbal and non-verbal, cultural and non-cultural as well as linguistic and non-linguistic for language teaching-and-learning to be carried out inside the classroom and, if possible, for English teachers to get along with.
\end{abstract}

Keywords: text, verbal and non-verbal, cultural and non-cultural, linguistic and non-linguistic, three-dimensional contextualization

\section{Introduction}

If a language is supposed to be a tool for the users to convey cultural information including "our ideas, our knowledge, our thoughts, our culture" (Halliday \& Hasan, 1989), the content to be shared with is nothing but culture. English education is therefore nothing more than an inter-cultural classroom communication, or, English is to be instructed more culturally than linguistically, or rather, language and culture is to be dealt with more as a whole than separately done from one another, as being listening, speaking, reading, and writing "plus culture" (Kramsch, 1993), which should have been a cardinal principle for a teacher to keep in mind and to follow in practice; yet, the problem is that language and culture are to be found, as if a rule, being taught always in a separate way, or rather, English language is taught, especially in China, far away from its culture in schools or classrooms time and time again and, what we have actually found in the classroom are such things as sound, word, and grammar with little more culture being left for students to enjoy and, perhaps, also for the teachers themselves to share and, in the end, the classroom itself by no means culturally attracted or fascinated to the students at all.

If, however, language is seen as a social practice, culture becomes the very core of language teaching.

YAN Jing, lecturer, master, School Library, Northwest University for Nationalities.

CHEN Si, postgraduate, School of Foreign Languages, Northwest University for Nationalities.

FEI Zi, professor, bachelor, School of Foreign Languages, Northwest University for Nationalities. 
Cultural awareness must then be viewed both as enabling language proficiency and as being the outcome of reflection on language proficiency (Kramsch, 1993, p. 8). And,

By its very nature, foreign language teaching is predicated that because we are all humans, we can easily understand each other provided we share the same code; all we have to do is to learn that code and use it accurately and appropriately. (Kramsch, 1993, p. 1)

Consequently, language and culture should be viewed as a whole where language is the carrier of the culture, while the culture the content for the carrier to hold in, which brings about language proficiency inside the classroom and, which also serves as the reflection on language proficiency of the classroom.

Therefore, what this paper attempts to do is to return to the place where English education should be or has to be, but not used to be. In other words, English language and culture are to be combined together as one thing in order that it be conducted both theoretically and practically inside the classroom in a inter-cultural linguistic environment, which is hypothesized, in this paper, as being a three-dimensional system, covering firstly verbal and non-verbal context; secondly, cultural and non-cultural context; and thirdly, linguistic and non-linguistic context, for English communication to occur both inter-linguistically and inter-culturally inside the classroom.

\section{What is Language?}

Multiply defined as such things as knowledge, habit, etc., as it has ever been, language can be culturally considered as the principal means by which people convey information of their cultural aspects or, in other words, which is used as kind of container for people to carry their cultural things, i.e., "our ideas, our knowledge, our thoughts, our culture" (Halliday \& Hasan, 1989), etc.. Simply, language is just a tool to be used both linguistically and culturally to convey cultural information which is dominant of a feature of a language and what a language teacher is to be aware of and, he or she has to keep it in mind that "The key to understanding language in context is to start not with language, but with context” (Hymes, 1972, p. xix).

\section{What is the Context for a Language to be Learned About?}

Linguistically, culture, a very complicated "central code" (Nostrand, 1989) of society as it has been, can be regarded as what people have to share or enjoy from beneath or behind the language. That is, culture is what is hidden beneath or behind the linguistic signs used in a conventional way, which is, again, something for a language teacher to be conscious of.

Obviously, language as text and culture as background are inseparable from one another, as Halliday and Hasan (1989) put it:

Text is language operative in a context of a certain situation and contexts are ultimately construed by the range of the texts produced within a community... One commonsense conception is... that our ideas, our knowledge, our thoughts, our culture are all there-almost independent of language and just waiting to be expressed by it. (Kramsch, 1993, p. 10)

Obviously, context is something by means of which language or text convey cultural information pragmatically. What context to text or language is, in other words, what water to plant-surviving.

\section{What is the Relationship Between Context and Text?}

Language, as text (code), reflects cultural preoccupations and constrains the way people think, which relates 
to culture as semantically encoded in the language itself on one hand; and, on the other hand, we recognize how important context is in complementing meanings encoded in the language, which concerns culture as expressed through the cultural use of the language (Kramsch, 1998). But, the question is-What kind of means is the language or in what way is context so important to complement meanings encoded in the language?

According to Kramsch, "language is the principal means whereby we conduct our social lives. When it is used in contexts of communication, it is bound up with culture in multiple and complex ways" (Kramsch, 1998, p. 3).

Then, how complex and multiplex is the text or language bound up with culture within the context?

According to Kramsch (1998), first, text or "language expresses cultural reality". In what way? The linguistic materials i.e., language, that people use refer to common experiences, which express facts, ideas, or events that are communicable since they refer to a stock of knowledge about the world that other people share and, the linguistic materials (language) also reflect their authors' attitudes and beliefs, their point of view, which are also those of others either linguistically or non-linguistically.

Secondly, text or "language embodies cultural reality". How? Members of a community or social group not only express experience, they also create experience through language. People give meaning to language through the medium they choose to communicate with each other when, for example, speaking on the telephone or face-to-face, writing a letter or sending an e-mail message, reading the newspapers, or interpreting a graph or a chart. And the way in which people use the spoken, written, or visual medium itself creates meanings that are understandable to the people they communicate with, for example, by means of a speaker's tone of voice, accent, conversational style, gestures, and facial expressions, etc., i.e., either in a verbal way or in a non-verbal way.

And thirdly, text or "language symbolizes cultural reality". Language is a system of signs, which is regarded as having itself a cultural value. Speakers identify themselves and, usually, through the using of language- - they view their language as a symbol of their social identity and, the prohibition of its use is often perceived by its speakers as a rejection of their social group and their culture either culturally or non-culturally (Kramsch, 1998).

Kramsch is quite right in finding the three aspects of the relationship between language and culture and something more mentioned above. But, when it comes to language teaching and learning, how can English teachers get aware of them both theoretically and practically, or rather, under what kind of circumstances can they master the situation they have to meet with inside the classroom? This is what has to be eventually found out throughout the paper.

\section{A Three-Dimensional Context Designed for Classroom Proficiency}

As mentioned above, language is regarded as the text, which lives within the context. But how does language live within a context and, again, how should the very the context or contexts be formed for the text or language to live, not to die?

According to Kramsch,

... the notion of a context is a relational one. ... it is shaped by people in dialogue with one another in a variety of roles and statuses. Because language is at the intersection of the individual and the social, of the text and discourse, it both reflects and construes the social reality called "context". (Kramsch, 1993, p. 67)

So, here, the question is: How do people give meanings to the language they use, or rather, how do we have 
the dialogue with the text in order to get the meaning intentionally according to the author and, finally, how are the contexts being shaped to mean differently in line with the author's intention? Those are the questions we have to answer and, the very contexts as are hypothesized to be established in this paper is to be a three-dimensional linguistic environment, which goes as follows:

\section{Context Shaped as Verbal and Non-verbal}

Here, we have, as an example, to show that a visitor to a city, carrying his luggage, looking very much lost, stops a passer-by:

Visitor: Excuse me, do you know where the Ambassador Hotel is?

Passer-by: Oh sure, I know where it is. (and walks away). (Yule, 1985)

Here, the visitor uses a form which is related to a yes-no-question (Do you know...?) to give his request, while the passer-by, quite unexpected to the visitor, answers the question as literally as he understands it (I know...), i.e., instead of responding to the very request, the passer-by replies the question, treating, as he does, the indirect speech act in real life as if it were a direct speech act in the classroom, which leads to his misunderstanding of the visitor.

In this scene, we find that the language the visitor, especially, the passer-by uses in the dialogue is rather "died" than otherwise, since the communication failed to be successful within the context of situation, because of misunderstanding from the passer-by which is being literal rather than il-literal, i.e., he understands it quite verbally but not non-verbally or something and, which reminds us of something "bookish" or "stupid" about him.

One more example, adopted from Widdowson (1978) is taken here to indicate that, in a conversational interaction, a great deal of what is meant non-verbally is, sometimes, not actually present in what is said verbally.

Nancy: That's the telephone.

Ron: I'm in the bath.

Nancy: O.K.. (Yule, 1985)

In view of the brief conversation above, we could characterize in the following way:

Nancy requests Ron to answer the telephone;

Ron just states the reason why he cannot answer it;

So Nancy undertakes to answer the telephone herself.

Why does this happen in the discourse? It is, perhaps, because the language-users have kind of knowledge about how conversational interaction takes place, which is not really something of literal or "verbal" knowledge but actually anything of il-literal or non-verbal logic. And also, perhaps, it is the case with which listener could ordinarily anticipate the speaker's intention that makes this whole complex process seem so understandable and unnecessarily remarkable, and from which we know the users' way being both literal and il-literal, or both verbal and non-verbal to convey information, which is to be regarded logically as the dialogue, being also both literal and il-literal, or verbal and non-verbal, between the readers and the text in the process of the interpretation of the discourse.

Obviously, in order to make language live rather than die within a context, we need to make it distinguishable between verbal context and non-verbal context so as to get the meaning which is given "by the 
way the participants perceive the context of situation and shape it through their verbal and non-verbal behavior" (Kramsch, 1993, pp. 49-50), or rather, either in a literal or in an il-literal way.

\section{Context Shaped as Cultural and Non-cultural}

Here we have an African-American student who has been sent to interview a black housewife in an inner city neighborhood, which serves as an example to show his failure in communicating with the husband who opened the door for him, smiling originally.

Husband: So y're gonna check out ma ol lady, hah?

Student: Ah, no. I only came to get some information. They called from the office.

(Husband, dropping his smile, disappears without a word and calls his wife.) (Gumperz,1982)

Failing, more culturally than linguistically, to infer from black husband's stylistic cues (the intonation, pronunciation typical of Black English Vernacular, as well as the lexical choice of "ol lady" for "wife", "check out" for "visit", etc., i.e., the husband's offered a solidarity from one African-American to another, yet the visitor, the student responds, quite opposite to what the husband expected, in "White Standard English" ("I" for /a/, "get" for /gi::t/), thereby showing that he is from an academic culture rather than the husband's "black" culture, which leads the interview to be quite stiff and unsatisfactory (Kramsch, 1993), which could, if necessary, be regarded as the way behind which the author hides his intention and, at the same time, which could also serve as kind of dialogue cultural and non-cultural between readers and the text to get the "deep structure" from beneath or behind the "surface structure" (Chomsk, 1957) both from "inside" and "outside" of the language.

Again, we have a sentence taken from the very beginning of the novel David Copperfield by Charles Dickens, which reads as:

"... I was remarked that the clock began to strike, and I began to cry, simultaneously" (Dikens, 1917, p. 1).

If the sentence needs translating into Chinese, the problem we have to face is: What is the ideal Chinese version for the word "clock"- is it an ordinary clock? No, culturally not at all. It has to be a "Church" Clock to strike; otherwise the story will remain western-culturally meaningless in Chinese. So the translation of the above sentence goes as: “听人家说, 教堂的钟声一响, 我便呱呱地来到了人间”, which must be a better interpretation of Charles Dickens, because we've got it from the "author" through the dialogue with the text both beyond and beneath an intercultural contextual relationship.

Similarly, as next case, we have the following to consider:

And Jesus said, Suffer little children,

And forbid them not to come onto me;

For of such is the kingdom of heaven (Bridges \& Weigle, 1960, p. 333). ${ }^{1}$

For the interpretation of the verse above, a little girl asked her mother, "Why does Jesus want little children to suffer?" The mother replied, "He doesn't. What makes you think so?" The child said, "That is what they taught us in Sunday school today."

Here, the child's problem remains, on one hand, something linguistic, which refers to the use of the word "suffer" in sense of "let" or "permit", and retains it only when it is used in sense of "undergo" or "endure". It thus

1 Taken from Bridges, R. and Weigle, L. A. The King James Bible, Word Book Nashville, Tennessee: Thomas Nelson, Inc. 1960, p. 333 . 
removes an ambiguity for which there is no warrant in the original language. While, on the other hand, what the child said leaves us Chinese a cultural problem, i.e., what should be the Chinese version for "Sunday school"? “星期天学校” or “主日学校”? It is, of course, the latter, for which there is no choice in target language that refers to the source language culturally.

Accordingly, we have to be always careful, while having the dialogue with text, not to make mistakes either culturally or non-culturally.

What the above examples remind us of is that the non-cultural context must be separated from the cultural context in which nationally recognized things are included so that such internationally recognized things as mood, intonation, pronunciation, logic, etc., are included for us to get the true sense of the text within a context not only culturally but also non-culturally.

\section{Context Shaped as Linguistic and Non-linguistic}

For the third kind of context, we have, as an example, a husband who is of middle class American background sitting in his living room one day, addressing his wife who is British and, the couple have been married and living in the United States for a number of years:

Husband: Do you know where today's paper is?

Wife: I'll get it for you.

Husband: That's O.K. Just tell me where it is, I'll get it.

Wife: No, I'll get it. (Gumperz, 1982)

In this scene, the husband is using a question, which could be literally interpreted as inquires of his wife about the location of the paper, while the wife does not reply directly and only offers to get the paper. Her "I'll" is so accented that it could be interpreted as "I will if you do not". The husband counter suggests that he had intended to ask for information, not to make a request. So, he also stresses "I'll". And the wife then reiterates her statement to emphasize that she intends to get it. The "I'll" is, by that time, highly stressed to suggest increasing annoyance. That is how, to some extent, the couple give meanings "by the way the participants perceive the context of situation and shape it through their verbal and non-verbal behavior" (Kramsch, 1993, ibid ), or rather, by using both their linguistic and non-linguistic ways, to his or her interlocutor, isn't it?

And again, we have a mother who is asking her eleven year old son that is about to go out in the rain:

Mother: Where are your boots?

Son: In the closet.

Mother: I want you to put them on right now. (Gumperz,1982)

Here, the mother is asking a question, which might be literally interpreted as concerning the location of the boy's boots. So the boy, making use of it, gives his mother the response with a statement about the location and, immediately his mother retorts with a direct request stressing on "right now", which is asking the boy to put on the boots immediately. Apparently, mother is actually annoyed at her son for not responding her initial question as a request in the first place.

And, at first glance, one might think that what is at issue here is the boy's failure to respond appropriately to his mother's indirect request. But here the directness itself is, in fact, a matter of social-cultural convention. And therefore, we find few people treat the American request, i.e., "Have you got the time?" as an indirect 
request. Consequently, the interpretative differences of this type in these two examples could have been found to be patterned in accordance with differences in gender and ethnic origin, or rather, culture, which makes linguistic aspects less attentive than non-linguistic ones in communication, which is, perhaps, why Susan Bassnett said that "... the process (of translation) involves a whole set of extra-linguistic criteria also" (Bassnett, 1980, p. 13).

And therefore, as for the third kind of context, we have to draw a clear distinction between something linguistic and something non-linguistic anyway in case there is something left out of consideration.

Needlessly to say, there must be something overlapped among the three kinds of contexts deliberated throughout the paper.

\section{Classroom Atmosphere Shaped as a Three-Dimensional Context}

If the three aspects of language interpretation mentioned above were made to be contextualized, we could have a contextualization system, or rather, contextualization cues (Kramsch,1993), which could, naturally and logically, be defined as a three-dimensional context for the classroom proficiency, i.e., for teachers to deal with all the problems they meet with verbally and non-verbally and, culturally and non-culturally, as well as linguistically and non-linguistically, and which could also serve as the designing made in this paper for the cognitive structure of the learners under the so-called three-dimensional circumstances of English education.

\section{Conclusion}

What we have done in this paper is actually to set up a three-dimensional context for language teaching-and-learning communication to be held on inside the classroom, or what we have hypothesized is to let it be not only directly linguistic and cultural, but also indirectly verbal and non-verbal, and cultural and non-cultural, as well as linguistic and non-linguistic, in order that we can let our classroom atmosphere be either cross-culturally or inter-culturally established, which could lead us to be nearing the target we have set forward for our English education and, through which we could develop our students not only into culturally competent, but also cross-culturally qualified learners.

\section{References}

Attinasi, J., \& Friedrich, P. (1994). Dialogic breakthrough: Catalysis and synthesis in life-changing dialogue. In B. Mannheim \& D. Tedlock (Eds.), The dialogic emergence of culture (pp. 33-53). Urbana: University of Illinois.

Bassnett, S. (1980). Cultural issues, translation studies (revised edition). London \& New York: Methuen.

Chomsky, N. (1957). Syntactic structures. The hague: Mouton.

Dikens, C. (1917). David Corpperfield. New York: The F.M. Lupton Publishing Company.

Ellis, R. (Ed.). (1987). Second language acquisition in context. Englewood Cliffs, N. J.: Prentice-Hall International.

Ellis, R. (1992). The classroom context: An acquisition-rich or an acquisition-poor environment?. In C. Kramsch \& S. McConnell-Ginet (Eds.), Text and context (pp. 171-186). Lexington, MA: D.C. Heath and company.

Gumperz, J. J. (1982). Discourse strategies. Cambridge: Cambridge University Press.

Hughes, G. H. (1986). An argument for culture analysis in the second language classroom. In J. M. Valdes (Ed.), Culture bound: Bridging the culture gap in the language teaching (pp. 162-169). NY: Cambridge University Press.

Howatt, A. P. R. (1984). A history of English language teaching. Oxford: Oxford University Press.

Halliday, M. A. K., \& Hassan, R. (1989). Language, context and text: Aspects of language in a social-semiotic perspective. Oxford: Oxford University Press. 
Hymes, D. H. (1972). Introduction. In C. B. Cazden, V. P. John, \& D. Hymes (Eds.), Functions of language in the classroom (pp. xi-vii). New York: Teachers College Press.

Kramsch, C. (1993). Context and culture in language teaching. Oxford: Oxford University Press.

Kramsch, C. (1998). Language and culture. Oxford: Oxford University Press.

Knowles, G. (2004). A cultural history of the English language. Beijing: Peking University Press (First published in Great Britain in 1979 by Arnold, a member of the Holdder Group).

Yule, G. (1985). The study of language. Cambridge: Cambridge University Press. 